\title{
Third World to demand new fund for scientific development
}

THIRD World countries are making a strong bid to have the creation of a new fund for scientific and technological development occupy a prominent position on the agenda of the United Nations Conference on Science and Technology for Development (UNCSTD), which takes place in Vienna at the end of August.

The new fund is currently referred to as the International Science and Technology Development financing system. It is among the proposals submitted to the UNCSTD secretariat last week by the Group of 77-the organisation which represents over 100 developing countries-as a possible redrafting of a proposed programme of action to be adopted by the conference.

At present there is still considerable disagreement among members of the Group of 77 over precisely what form the fund should take and how it should operate. However, some broad principles have been agreed, such as the fact that it should operate within the United Nations system, and that it should also provide relatively stable and continuous funding, to avoid problems for scientific programmes caused by intermittent or fluctuating support.

Other proposals that have been made are that the fund should be made up of contributions based on agreed percentage of the average deficit in the trade balance in manufactured goods between the developing and developed countries; that it be financed in part through a reduction in armaments expenditure by the developed countries; and also that further funding might come from a tax paid by developed countries to compensate for the braindrain from developing countries.

The developed countries, however, have already made it known that they will be very reluctant in Vienna to accept any proposals which will require to provide substantial increases of funds. The issue is therefore likely to be one of the most hotly discussed during the conference.

The two other main issues likely to generate debate, it emerged from last week's meeting of the conference's preparatory committee in New York, are the development of appropriate institutional mechanisms-including the rearrangement of responsibilities for science and technology within the UN system-to support any policy recommendations made by the conference, and possibly some specific proposals for ways of stimulating collaborative research on topics of particular interest to developing nations.
The developing nations are more concerned at present about financial mechanisms and about institutional arrangements-the developed nations about specific research proposals. As things stand at present it seems unlikely that any major changes will emerge directly from the conference itself (restructuring of the UN system, for example, can only be done by the General Assembly). But there are still hopes that the conference will produce guidelines representing a consensus on how each of these three items should be approached.

The main development in the conference preparations since the last meeting of the preparatory committee in New York in February has been the efferts of the Group of 77 to develop a unified position which the developing nations can present at Vienna.

A working party of the Group of 77 met in New York for the first two weeks in April to prepare a set of amendments to the preliminary draft programme of action which has now been drawn up by the secretariat under three headings: strengthening the scientific and technological capacities of developing countries; restructuring the existing patterns of international scientific and technological relations; and strengthening the role of the United Nations in science and technology and the provision of increased financial resources.

In parallel to this effort the economic commission for Latin America organised a meeting of a group of experts in Lima, Peru, in March to discuss possible financing mechanisms to provide additional support for science and technology in developing countries,

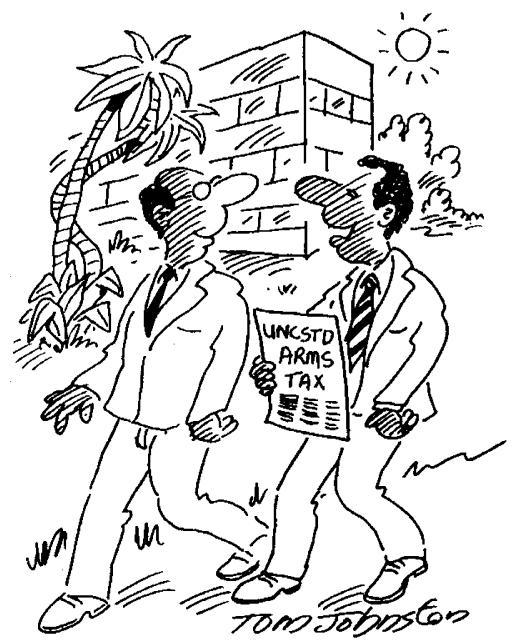

"Every time they make a bomb, we make a killing!" making various proposals which, although not officially endorsed by ECLA, have been partially amalgamated into the Group of 77 .

At the end of last week, the Group of 77 presented to the preparatory committee its suggestion on revising the first part of the draft programme of action, that which deals with internal arrangements within countries for developing science and technology.

Many of the suggestions such as the need to establish science and technology policies as part of general development policies, and to encourage cooperation between developing and developed countries, as well as between developing countries themselves, had already been made by the secretariat itself on the basis of the suggestions contained in the various national and regional papers which have been prepared and submitted as part of the planning process for this conference.

With regard to financial resources, the group of 77 says that present funding mechanisms for enhancing national science and technology systems "are highly unsatisfactory both from the qualitative and quantitative considerations" and adds that experience has shown that "there is need for a more effective financing system within the United Nations system for strengthening the science and technology capacities of developing countries".

In general the developing countries suggest that developed countries should devote on an annual basis $0.05 \%$ of their gross national product to the solution of scientific and technological problems of developing countries, and devote at least $10 \%$ of their R \& D expenditure to programmes designed to solve problems of specific interests to developing countries.

More specifically they recommend the setting up of an International Science and Technology Development Financing System to provide financial resources to supplement national science and technological financing capabilities.

Precise details of how this system would work were still under discussion by the Group of 77 at the beginning of this week. In an earlier draft of possible recommendations prepared by the working party, however, it was suggested that any new system of financing be based on a number of features, including provision that money be made available on a predictable and continuous basis, and that it should be based on a linked to international economic parameters which reflect the present asymmetries between countries in technical capacity.

Appropriate provision should be made, the working party suggested, for the financing system to involve the use of regional funds, for which the ad- 
ministrative responsibility would be bestowed on the developing countries themselves, while overall responsibility would rest with the UN general assembly. points are likely to occupy much of the time up to the Vienna conference. Meanwhile, in an attempt to make sure that something of a more immediately practical nature emerges from UNCSTD, various countries are sup-
Detailed discussion on these various

porting proposals that specific efforts should be made to establish projects in areas requiring greater research. Belgium, for example, submitted a resolution to the preparatory committee last week suggesting five areas for international collaborative research: solar energy, rural development technologies, tropical diseases, methods of increasing food production, and an inventory of natural resources.

David Dickson

\section{Agricultural research centres transformed}

THE dozen international agricultural research centres set up between 1959 and 1976 to conduct research into problems of tropical agriculture have had considerable influence on the national research systems of many developing countries as well as on the crops and methods used by farmers. The very changes the international centres have stimulated, however, have in turn resulted in changes being made to the mode of operation of the centres themselves so that they are no longer working to the rules laid down when the first, the International Rice Research Institute, was set up twenty years ago.

Speaking to a small gathering at the Science Policy Research Unit, University of Sussex last week, Dr Edward Clay of the university's School of African and Asian Studies said that the international centres had greatly influenced the way scientists in third world countries "perceive the research they're to carry out". In particular ever since IRRI and the International Center for the Improvement of Maize and Wheat (CIMMYT), the first two centres to be set up, achieved considerable success in breeding highyielding dwarf varieties, most research on increasing yields for all sorts of crops in many countries has centred on finding dwarf varieties.

In India, for example, rice research has tended to focus on light-yielding semi-dwarfs for irrigated land. $67 \%$ of rice breeding is oriented towards irrigated rice, even though only $28 \%$ of the land used for rice cultivation is irrigated. And almost all the new varieties developed have been semidwarfs. Only 5\% are suited for deep water although $40 \%$ of the land used for rice growing is under deep water.

According to Dr Clay, the international centres cannot be held entirely responsible for this mismatch of research to needs although it is highly likely that they have had some influence. In the case of rice research, for example, IRRI has mainly concentrated on irrigated rice-simply because of the local conditions around its home in the Philippines.

The centres' influence, however, claims Dr Clay, extends beyond the individual scientist to the very agricultural policy of developing countries. "Experts were put into the international centres and were successful", he says "therefore the model of a centre was seen as a good recipe for success". More international centres were built and individual countries began to build their own single purpose centres. The Bangladesh government, for example, decided to create one specific rice research institute-"very large, costly and capital intensive with well-trained scientists". This was a new idea for an individual country-even countries with a highly organised research effort such as the US and Japan had not concentrated their research on just one topic into one place.

When IRRI and CIMMYT were first set up, they were intended to be solely research centres where Western scientists could apply certain techniques which had proved beneficial in agricultural research for temperate zone crops to tropical crops. As the spread, however, and individual developing countries began to take up their methods, they have played an increasing role in educating third world scientists and organising exchanges. With the creation of the Consultative Group for International Agricultural Research (CGIAR) "to raise funds and establish research policies" for the centres and the creation of more centres in different parts of the world, their operation has gradually become more bureaucratic.

"We now have well-defined bureaucratised institutions", according to Dr Clay. "This was not true of the original centres. In expanding and replicating the original model we've now got something quite different". There is now pressure for the centres to work much more with developing countries than was initially intended. And, according to Dr Clay, as they are essentially funded by industrialised countries this has put them into a complicated relationship between the aid-donors and their recipients.

Judy Redfearn influence of these first two centres

\section{Pre-UNCSTD colloquium planned}

Preparatrons ror the Colloquium on "Science, Technology, and Society" to be held by the UN Committee on the Application of Science and Technology to Development (ACAST) in Vienna next August immediately before UNCSTD, were the main item on ACAST's agenda when it met in Geneva recently. At the Colloquium 200 invited representatives of the world scientific and technological community will help formulate a document for discussion at UNCSTD.

During the first week of the ACAST meeting it became apparent that the Colloquium is seen only in terms of certain items of the agenda of UNCSTD. For whatever reasons, the members of ACAST seem to have forgotten their hitherto jealously guarded role as an independent advisory committee, and limited themselves mainly to points they had been asked to consider by UNCSTD Secretary-General, José da Costa.

However, da Costa himself possibly helped to harden ACAST's attitude. His personal intervention on a flying visit, during which he did not even stop to answer many of the questions he inspired, appeared to reflect considerable pessimism as to the outcome of his own Conference. Seeing less than a fifty-fifty chance of any concrete results, he feared it would be only a "conference verbale", within which ideas on, amongst other things, new forms of cooperation between North and South, as well as within the South might at best appear in the form of recommendations.

Da Costa's statement was also noteworthy for a sudden and highly emotional attack on the way in which his conference is being treated by the media, in particular by the "Lund Letter", published by an internationally-oriented group in Sweden, and which he singled out as "nordique et paranoiaque".

A second factor which further enlivened the ACAST proceedings was what looked remarkably like an attempt on the part of UNESCO, through their representatives at the meeting, to take over the whole Colloquium, albeit still disguised as an ACAST-sponsored meeting. Whether this was because of their frustration at the admittedly somewhat tardy and, to some observers, impractical way in which the Colloquium was being planned and organised, is not clear.

However, here the members of ACAST closed their ranks and refused to be stampeded by UNESCO's probably justified calls for urgency. 